\title{
Th2 biased upper airway inflammation is associated with an impaired response to viral infection with Herpes simplex
} virus $1^{*}$

\author{
Feng Lan'\$ ${ }^{15}$ Xiang Dong Wang ${ }^{3 \$}$, Hans J. Nauwynck², Gabriele Holtappels', \\ Luo Zhang ${ }^{3}$, Sebastian L. Johnston ${ }^{4}$, Nikolaos G. Papadopoulos ${ }^{5,6}$, \\ Claus Bachert ${ }^{1,7}$, Nan Zhang ${ }^{1}$ \\ ' Upper Airway Research Laboratory, Department of Otorhinolaryngology, Ghent University Hospital, Ghent, Belgium \\ ${ }^{2}$ Laboratory of Virology, Faculty of Veterinary Medicine, Ghent University, Merelbeke, Belgium \\ ${ }^{3}$ Department of Otolaryngology Head and Neck Surgery, Beijing TongRen Hospital, Capital Medical University, Beijing, P.R. China \\ ${ }^{4}$ Airway Disease Infection Section, National Heart \& Lung Institute, Imperial College London, United Kingdom \\ ${ }^{5}$ Allergy Department, 2nd Pediatric Clinic, University of Athens, Greece \\ ${ }^{6}$ Centre for Paediatrics \& Child Health, Institute of Human Development, University of Manchester, United Kingdom \\ 7 Division of ENT Diseases, Clintec, Karolinska Institute, Stockholm, Sweden
}

Rhinology 54: 141-149, 2016

DOI:10.4193/Rhino15.213

*Received for publication:

July 22, 2015

Accepted: September 12, 2015

\$ These authors contributed

equally to this work.

\begin{abstract}
Background: We aimed to elucidate possible differences in antiviral defense in chronic rhinosinusitis with nasal polyps (CRSwNP) mucosal tissue compared to healthy mucosal tissue (HMT) upon herpes simplex virus 1 (HSV1) exposure.

Methodology: HMT and CRSwNP samples were infected with HSV1. We visualized the virus location by immunofluorescence and monitored invasion by a score. The mediators Interferon (IFN)- $\alpha$, IFN- $\beta$, IFN- $\lambda$, IFN- $\gamma$, Interleukin (IL)- 6 , IL- $1 \beta$, Tumor necrosis factor (TNF)- $a$, IL-17, IL-5, IL-10 were measured in culture supernatants at baseline and at $24 \mathrm{~h}, 48 \mathrm{~h}$ and $72 \mathrm{~h}$ after virus incubation.

Results: CRSwNP mucosal tissue showed a significant deficit in IFN- $\gamma$ and IL-17 release within 24 to 72 hours after infection in comparison to HMT, at the same time releasing significantly more pro-inflammatory cytokines including IL-1 $\beta$ and TNF-a. These findings were associated with significantly higher viral invasion scores at 48 and $72 \mathrm{~h}$ in CRSwNP mucosa compared to those for the HMT.

Conclusions: We demonstrate for the first time in a human ex-vivo mucosal model that the inadequate response of CRSwNP may be associated with a deeper intrusion of viruses into the mucosal tissue, and may contribute to more and longer symptoms upon acute infection, but also to the persistence of inflammation in CRSwNP tissue.
\end{abstract}

Key words: human ex vivo mucosa model, herpes simplex virus 1 infection, nasal polyps, interferon- $\gamma$

\section{Introduction}

Chronic rhinosinusitis with nasal polyps (CRSwNP) represents a preferentially eosinophilic type of inflammation of the upper airways, characterized by the overproduction of IL-5, eosinophilcationic protein (ECP) and immunoglobulin (Ig)E; CRSwNP also is frequently associated with comorbid asthma ${ }^{(1)}$. Viral infections are known as the most frequent cause of acute rhinitis and may cause asthma exacerbations in children and adults, with human rhinoviruses being identified as the most prominent, but not exclusive agent ${ }^{(2-4)}$. Although natural and experimental rhinovirus infections have been studied extensively with respect to clinical manifestation and pathophysiological responses in healthy subjects $(5,6)$, little is known about viral infections in patients with chronic inflammatory disease of the nose and sinuses such as 


\section{CRSWNP.}

Herpes simplex virus 1 (HSV1) infections are highly prevalent in humans. HSV1 is characterized by a comparatively high global sero-prevalence with rates of infection between $65 \%$ and $90 \%$ worldwide ${ }^{(7-9)}$. Although people infected with HSV often develop labial or genital lesions, the majority are either undiagnosed or display no physical symptoms; individuals with no symptoms are described as asymptomatic or as having subclinical herpes. Findings from a recent study have shown that $8 \%(2 / 23)$ of human nasal polyps may be infected with HSV1 at a given moment in time; although this seems a low incidence, it underlines the possible role of HSV1 in upper airway disease. Furthermore, HSV infection is a risk factor for nasal carriage of Staphylococcus (S.) aureus in human immunodeficiency virus (HIV)-infected patients (11). For herpes virus infection in animals, the nasal mucosa is considered the primary site of replication ${ }^{(12)}$.

It was recently shown that the response to viral infections (rhinovirus) is also impaired in asthmatics vs. healthy controls, with a deficit in the mucosal production and release of interferons in response to the viral challenge, which may impair the mucosal defense and allow the virus to replicate at high rate ${ }^{(13)}$. The mucosa in asthmatics is characterized by a Th2 bias, similar to the situation in CRSwNP. In the current study we therefore aimed to study the cytokine response related to a viral agent, HSV1, in our CRSwNP whole mucosal tissue model compared to control samples to elucidate possible differences in antiviral defense.

\section{Methodology}

\section{Nasal mucosa tissue}

Inferior turbinate healthy mucosal tissue (HMT) was obtained from 7 non-allergic patients (average age 36 years (range: 2352)) scheduled for turbinate surgery due to septal deviations or turbinate hypertrophy without asthma and other diseases. Nasal polyp tissues were obtained from 7 patients with CRSwNP (average age 48.5 years (range: 17.4-68.8)) by endoscopic sinus surgery at the department of Oto-Rhino-Laryngology, Ghent University Hospital. The diagnosis of sinus disease was based on history, clinical examination, nasal endoscopy, and CT scanning of the sinuses according to the European Position Paper on Rhinosinusitis and Nasal Polyps ${ }^{(14)}$. The atopic status of patients was evaluated by skin prick tests (SPTs) with the European standard panel of 14 inhalant allergens. Negative and positive controls ( $10 \mathrm{mg} / \mathrm{mL}$ histamine solution) were included with each SPT. One CRSWNP patient had a positive skin prick test, two patients reported mild asthma, and one patient reported aspirin intolerance.

The ethics committee of the Ghent University Hospital approved the study, Belgium registration number B670201317380; all patients were asked to refrain from oral corticosteroids or antibiotics 4 weeks and topical corticosteroids 2 weeks preoperatively and gave their written informed consent.
Measurement of cytokine and IgE levels in tissue homogenates

Freshly obtained tissue specimens were homogenized, as previously described ${ }^{(15)}$, and assayed for IL-5, IFN- $\gamma$ and IL-17, by using commercially available Quantikine ELISA kits (R\&D Systems, Minneapolis, MN, USA) following the instructions of the manufacturer. IgE and ECP were measured by using the UNICAP system (Pharmacia, Uppsala, Sweden).

\section{HSV1 stocks}

HSV1 (ATCC, VR-733, strain F) was purchased from the American Type Culture Collection (ATCC; Rockville, MD, USA) and propagated to large quantities by infection of African green monkey kidney (Vero) cells (ATCC CCL-81; Rockville, MD, USA). The virus strains were passaged twice and diluted in serum-free medium (50\% RPMI medium 1640 (Invitrogen, Merelbeke, East Flanders, Belgium) and Dulbecco's Modified Eagle Medium (Invitrogen, Belgium), $50 \mathrm{IU} / \mathrm{mL}$ penicillin (Invitrogen, Belgium) and $50 \mu \mathrm{g} /$ $\mathrm{mL}$ streptomycin (Invitrogen, Belgium) to a final concentration of $10^{7} \mathrm{TCID} 50$ (50\% tissue culture infectious dose of a virus) $/ \mathrm{ml}$. Tissue culture medium (TCM, contains equal amounts of RPMI medium 1640 (Invitrogen, Merelbeke, East Flanders, Belgium) and Dulbecco's Modified Eagle Medium (Invitrogen, Belgium)) were used for all subsequent experiments involving infection of nasal turbinate tissue ex-vivo.

\section{Culture and infection of healthy nasal turbinate and nasal polyp explants with HSV1}

The set up is depicted in Figure 1. Nasal turbinate and nasal polyp tissue obtained from each patient following surgery was immediately washed three times with serum-free medium supplemented with antibiotics $(50 \mathrm{IU} / \mathrm{mL}$ penicillin (Invitrogen, Belgium) and $50 \mu \mathrm{g} / \mathrm{mL}$ streptomycin (Invitrogen, Belgium) and cultured according to the following protocol. The washed tissue explant was cut into smaller cubes approximately $25 \mathrm{~mm}^{2}$ in size. Nasal tissue cubes of each turbinate or nasal polyp explants were used for further investigation, divided into two equal groups of two cubes each (Group 1 (A,B wells) = HSV1 infection group; Group 2 ( $A, B$ wells) = control, non-infection group, Group $1 \mathrm{~B}$ and Group 2B cubes were divided into 2 parts before any treatment ). Each cube was placed with the epithelial surface upwards on sterile fine-meshed gauze in a 6-well tissue-culture plate (Falcon, BD Biosciences, Erembodegem, East Flanders, Belgium) and $3 \mathrm{ml}$ serum-free medium supplemented with antibiotics was added to each well to create an air-liquid interface. All tissue cubes were conditioned as explant cultures by incubation for $24 \mathrm{~h}$ at $37^{\circ} \mathrm{C}$ in $5 \% \mathrm{CO}_{2}$ in air atmosphere, and then transferred to a 24-well tissue-culture plate (Falcon, BD Biosciences, Belgium). Groups 1 tissue cubes were inoculated with $1.0 \mathrm{~mL}$ inoculum containing $10^{7} \mathrm{TCID} 50$ of HSV1, and $1.0 \mathrm{~mL}$ of serum- 


\section{Inferior turbinate healthy mucosal tissue/ Chronic rhinosinusitis with nasal polyps mucosal tissue \\ Incubation for $24 \mathrm{~h}$ at $37^{\circ} \mathrm{C}$}

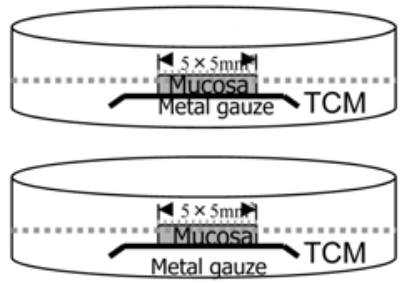

Further incubate $24 \mathrm{~h}$ and collect the supernatant and the tissue

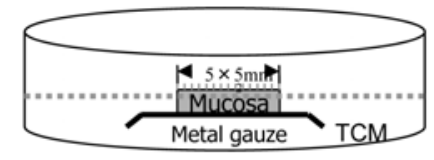

Infection for $1 \mathrm{~h}$ at $37^{\circ} \mathrm{C}$

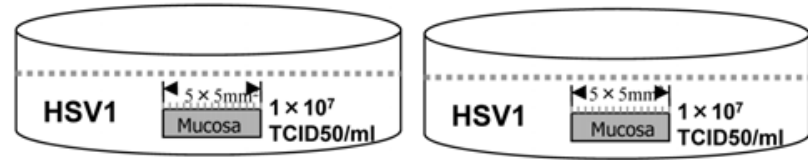

Wash 3 times with TCM

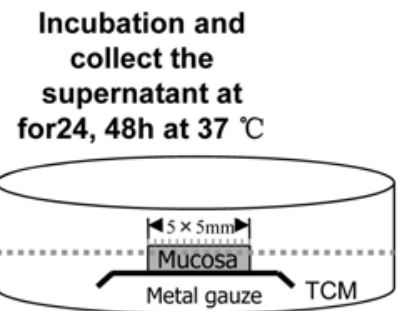

Incubation and collect the half of the tissue at $24,48 h$ respectively

Figure 1. Study flow. Culture and infection of nasal turbinate healthy mucosa tissue and nasal polyp explants with HSV1: Nasal tissue cubes were divided into two equal groups of two cubes each (Group 1 = HSV1 infection group; Group 2 = control, non-infection group). Groups 1 tissue cubes were inoculated with HSV1, and serum-free medium was added to the tissue cubes in Groups 2 as mock-condition.

free tissue culture medium (TCM) was added to the tissue cubes in Groups 2 as mock-condition, all tissue cubes were incubated for $1 \mathrm{~h}$ at $37^{\circ} \mathrm{C}$ in $5 \% \mathrm{CO}_{2}$ in air atmosphere. All tissue cubes were washed three times, transferred onto sterile fine-meshed gauze and incubated in a 6-well tissue-culture plate for either $24 \mathrm{~h}$ or $48 \mathrm{~h}$ under air-liquid interface culture conditions as before. At the end of each incubation period, the culture supernatants from Group 1A and Group 2A were collected, and tissue cube parts from Group 1B and Group 2B were collected, weighted and snap-frozen respectively at $24 \mathrm{~h}$ or $48 \mathrm{~h}$ time point, store at $-80^{\circ} \mathrm{C}$ for further evaluation. In order to investigate the spontaneous release, the tissue cubes which underwent $48 \mathrm{~h}$ culture were transferred to a 6-well tissue-culture plate with fresh tissue culture medium for a final $24 \mathrm{~h}$ incubation period (in total $72 \mathrm{~h}$ tissue incubation) on fine-meshed gauze at an air-liquid interface. At the end of the culture, the culture supernatant were collected and the tissue cubes were weighed and snap-frozen in liquid nitrogen and stored at $-80^{\circ} \mathrm{C}$, until further assessment. In the process of developing this model, we used uninfected vero cell lysates, heat inactivated HSV1 and tissue culture medium (TCM) as controls vs HSV1; as the controls showed the same morphology and cytokine response patterns, we here only used TCM as control.
Immunofluorescence staining for evaluation of HSV1 invasion

As previously reported ${ }^{(16,17)}, 10$ serial cryosections (5um per section) of each tissue cube were incubated for $1 \mathrm{~h}$ at $37^{\circ} \mathrm{C}$ in the presence of mouse anti-HSV1-gD antibodies (Santa Cruz, Heidelberg, Baden-Wurttemberg, Germany) (100 mg/mL, 1:100 in $10 \%$ NGS) or mouse lgG2 as an isotype specific negative control antibody (Dako, Glostrup, Region Hovedstaden, Denmark). Following three washings with PBS, the sections were incubated for a further $1 \mathrm{~h}$ at $37^{\circ} \mathrm{C}$ in the presence of goat anti-mouse-Texas Red antibodies (Molecular Probes, Invitrogen, Belgium) (2 mg/ $\mathrm{mL}, 1: 50$ in $10 \% \mathrm{NGS}$ ).

Immunofluorescence-stained slides were evaluated for viral invasion by viewing at $x 63$ magnification using a fluorescence microscope (Axioplan 2, Carl Zeiss, Gottingen, Lower Saxony, Germany). All stained slides were evaluated by two independent observers, who were blinded to the tissue-treatment protocol and assessed the entire epithelium in each section by viewing up to 8-10 adjacent fields.

HSV1 invasion in each field was graded on a 5-point scale $(0=$ epithelium not infected, 1 = epithelium superficially infected, 2 = basal cells infected, 3 = basement membrane and HSV1 colocalisation, HSV1 do not penetrate the basement membrane, $4=$ HSV1 penetrated the basement membrane into the lamina 

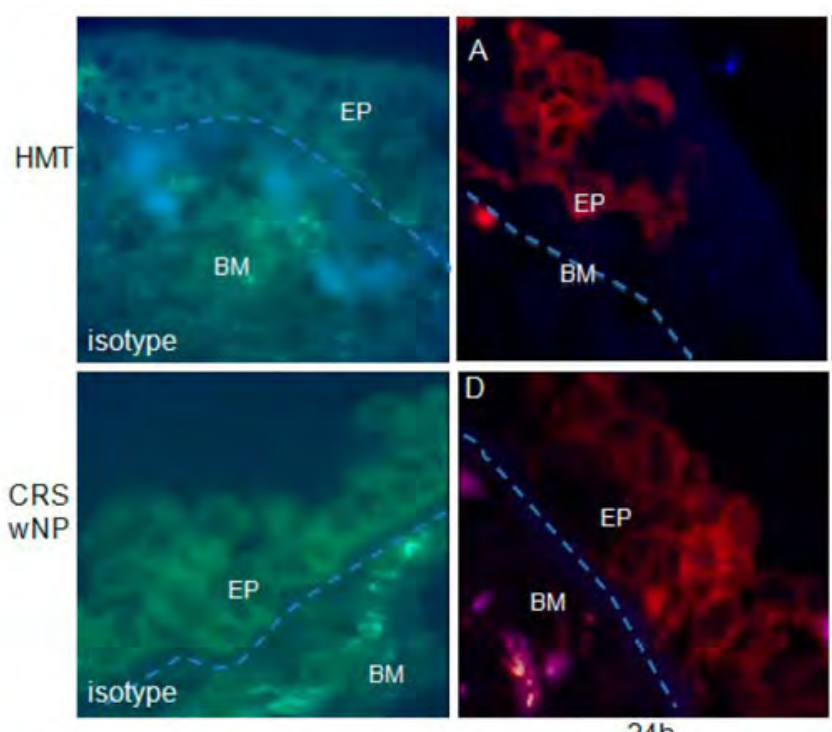

$24 \mathrm{~h}$
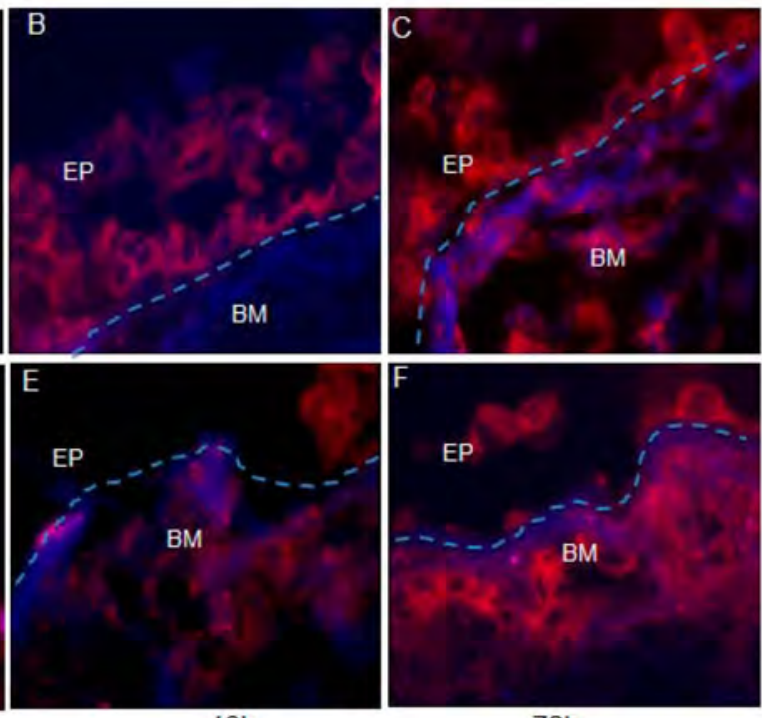

$48 \mathrm{~h}$

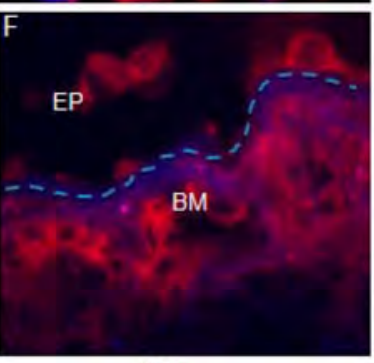

$72 \mathrm{~h}$

G

Invasion score of nasal mucosa Means (1SEM)

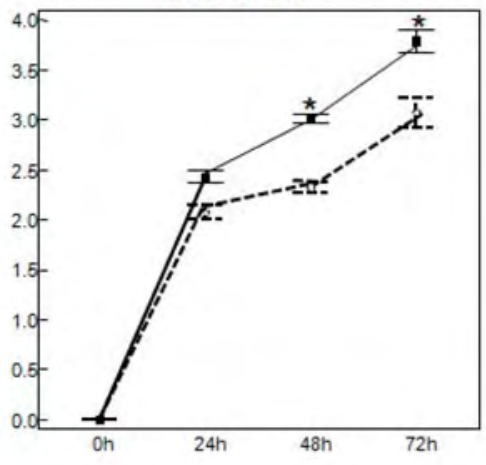

$\because$ CRSWNP

Figure 2. Immunofluorescence-stained sections of inferior turbinate healthy mucosal tissue (HMT) and nasal polyp tissue samples (CRSwNP) after HSV1 infection. Invasion score of HMT and CRSwNP tissue samples by HSV1. Results are presented as mean scores + SEM for HMT from 7 patients and CRSwNP from 7 patients. ${ }^{*}<<0.01$. Isotype: mouse lgG2 antibody on the sections of the tissue samples after $24 \mathrm{~h} H S V 1$ infection. Red is the positive HSV1 signal.

propria).

The mean of total scores in the ten sections on each slide was used as the final invasion score for each explant.

\section{Inflammatory cytokines were measured by ELISA in tissue culture supernatants}

Inflammatory mediators IFN- $\gamma$, IL-6, IL-1 $\beta$, TNF- $\alpha$, IL-17, IL-5, IL-10 were measured in culture supernatants at baseline and at $24 \mathrm{~h}$, $48 \mathrm{~h}$ and $72 \mathrm{~h}$ after virus incubation by means of commercially available Quantikine ELISA kits (R\&D Systems, Minneapolis, MN, USA). IFN- $\beta$ (Invitrogen), IFN- $\alpha$ (Invitrogen), and IFN- $\lambda$ (R\&D systems, USA) release was measured in culture supernatants at baseline and at $24 \mathrm{~h}, 48 \mathrm{~h}$ and $72 \mathrm{~h}$ after virus incubation, by using ELISA, according to the manufacturer's instructions.

\section{Statistical analysis}

Data were expressed as median and interquartile ranges (IQR). The Kruskal-Wallis test was used to assess the significance of intergroup variability; the Wilcoxon test was used for paired comparisons, and the Mann-Whitney U 2-tailed test was used to assess significance for between-group comparisons. P values $<$ 0.05 were considered to be statistically significant.

\section{Results}

Patient characteristics, cytokines and IgE levels in tissue homogenates

The two groups of patients were comparable in terms of clinical characteristics, allergic status and comorbid disease. At baseline, tissues from CRSwNPs showed significantly higher total IgE, ECP 
A

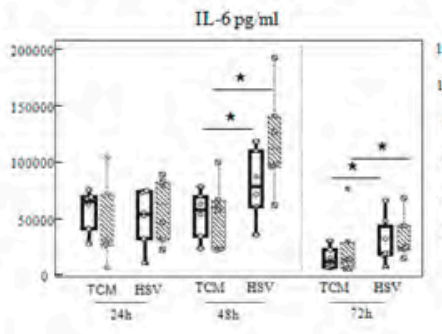

$\square$ HMT

CRSwNP
IL- $13 \mathrm{pg} \mathrm{ml}$

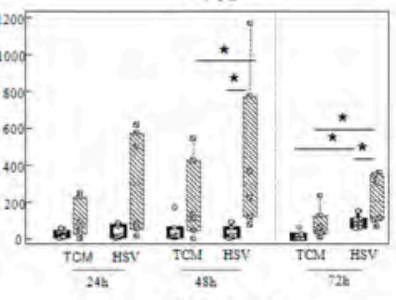

TNF $\alpha(\mathrm{pg} / \mathrm{ml})$

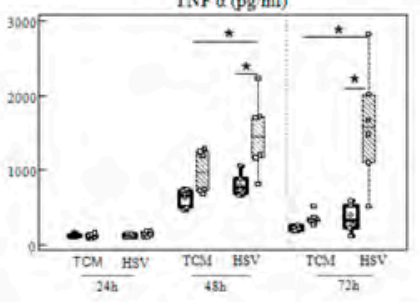

IFN $\beta$ pg ml
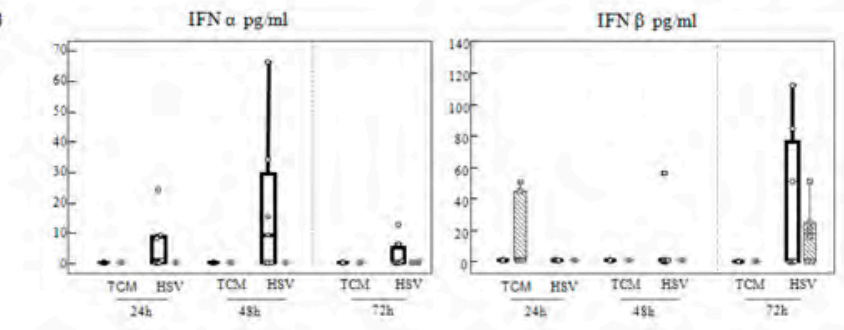

IFN $\lambda \mathrm{pg}$ ml
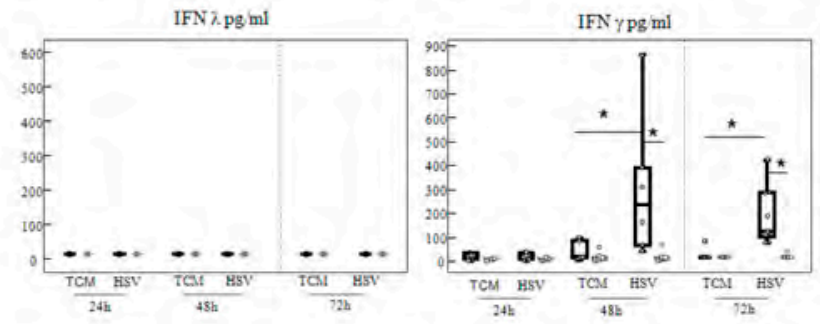

c
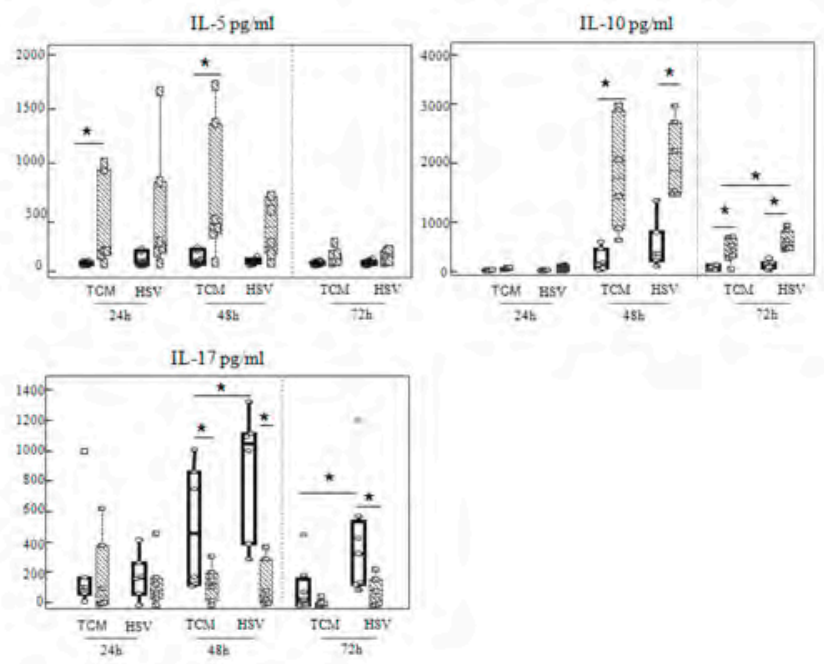

Figure 3. Inflammatory mediator release after HSV-1 infection. Data were expressed as median and interquartile ranges (IQR). * P value $<0.05$. HSV1 induced. (A) a significant release of IL-6 after $48 \mathrm{~h}$ and $72 \mathrm{~h}$ in both HMT and CRSWNP tissues, the release of TNFa was significantly increased after 48 and 72 hours in CRSwNP only; (B) a significant increase of IFN- $\gamma$ release in HMT samples at 48 and 72 hours, but no induction of IFN- $\gamma$ in CRSwNP tissue; (C) a significant IL-17 release in HMT but not in CRSwNP mucosal tissue. There was a significantly $(P<0.05)$ higher spontaneous release of IL-5 at 24 and 48 hours in CRSWNP vs. HMT, but this was independent from the impact of HSV infection. A significantly increased release of IL-10 was observed in CRSwNP vs. HMT at 48 and 72 hours, which was significantly further increased by HSV1 infection at 72 hours. No increase in IL-10 was observed in HMT samples. TCM: tissue culture medium, indicating the uninfected culture. 
Table 1. Cytokines and lgE levels in tissue homogenates.

\begin{tabular}{|c|c|c|c|c|}
\hline Tissue & $\begin{array}{l}\text { Detection limit after } \\
\text { sample handling } \\
\text { dilution }\end{array}$ & $\begin{array}{c}\text { Inferior turbinate healthy } \\
\text { mucosal tissue (HMT) } \\
\text { median (IQR) }\end{array}$ & $P$ value & $\begin{array}{l}\text { Chronic Rhinosinusi- } \\
\text { tis with nasal polps } \\
\text { (CRSwNP) } n=7 \text { median } \\
\text { (IQR) }\end{array}$ \\
\hline Total lgE (kUA/L) & 1.9 & $16.6(9,24-42.3)$ & 0.003 & $205.3(56.4-244.2)$ \\
\hline $\mathrm{ECP}(\mathrm{ug} / \mathrm{ml})$ & 11.0 & 357.5 (98-504.3) & 0.015 & 13609.7 (5236.3-20570) \\
\hline IL-5 (pg/ml) & 7.0 & $\mathrm{BDL}$ & 0.007 & 263.7 (39.4-510.4) \\
\hline IFNץ (pg/ml) & 42.9 & $42.9(42.9-77.2)$ & n.s. & $\mathrm{BDL}$ \\
\hline IL-17 (pg/ml) & 7.0 & BDL & n.s. & $7(7-17.6)$ \\
\hline
\end{tabular}

BDL: below detection limit; n.s.: not significant

and IL-5 concentrations vs inferior turbinate tissues from control samples $(p<0.05)$. IL-17 was below detection limit in both groups, whereas IFN- $\gamma$ could be detected in 3 control tissues (Table 1).

HSV1 replicates and invades in the nasal mucosal tissue after 24, 48 and 72 hours cultivation

Infection of the nasal inferior turbinate mucosal tissue explants with HSV1 led to focal infection of outer epithelial cells within $24 \mathrm{~h}$ (Figure 2A) with distribution up to the basement membrane and damage of epithelial structural integrity after $48 \mathrm{~h}$ (Figure 2B). Incubation of the tissue for $72 \mathrm{~h}$ (Figure $2 \mathrm{C}$ ) following inoculation with HSV1 led to infection of basal epithelial cells, followed by the loss of epithelium and subsequent invasion of HSV1 into the lamina propria. In contrast, HSV1 infected the whole epithelium of nasal polyp tissue within 24h (Figure 2D), causing epithelial damage already after $48 \mathrm{~h}$ (Figure 2E), and significant damage of the epithelium and invasion into the lamina propria through the basement membrane after $72 \mathrm{~h}$ (Figure 2F).

The depth of mucosal invasion for HSV1 in nasal polyp tissue was similar to turbinate mucosa at $24 \mathrm{~h}$, but the invasion scores at 48 and $72 \mathrm{~h}$ were significantly higher than those for the turbinate mucosa $(p<0.05)$ (Figure $2 G$ ), indicating that more viruses infected deeper mucosal layers.

Immunofluorescence staining for untreated cryosections was also performed by using anti-HSV1-gD monoclonal antibodies. Neither in those cryosections nor in TCM treated HMT and CRSwNP tissues, HSV1 was detectable.

\section{Inflammatory mediator release after HSV-1 infection} HSV1 induced a significant release of IL- 6 after $48 \mathrm{~h}$ and $72 \mathrm{~h}$ in both HMT and CRSWNP tissues, without significant difference between groups. However, in CRSwNP samples, we could demonstrate a significant release of IL-1 $\beta$ at $48 \mathrm{~h}(\mathrm{p}=0.031)$, whereas no IL-1 $\beta$ was released in HMT before $72 \mathrm{~h}$ post inocula- tion (Figure $3 \mathrm{~A}$ ); the concentration of IL-1 $\beta$ in the supernatants was significantly higher in CRSwNP compared to HMT at $72 \mathrm{~h}$ $(p=0.01)$. In line with these findings, the release of TNFa was significantly increased after $48(p=0.031)$ and 72 hours $(p=0.031)$ in CRSwNP only.

IFN-a could be detected in 4 out of 7 HMT samples after HSV1 incubation at 24 and 48 hours, but not in any CRSwNP samples; however, this difference did not reach significance. IFN- $\beta$ was found in the supernatants of 3 HMT and 4 CRSwNP samples at 72 hours incubation. IFN- $\lambda$ was not detectable at any of the time points in any of the samples. However, there was a significant increase of IFN- $\gamma$ release in HMT samples at $48(p=0.031)$ and 72 hours ( $p=0.016)$, but no induction of IFN- $\gamma$ in CRSwNP tissue upon HSV1 infection (Figure 3B).

There were also significant differences in terms of $\mathrm{T}$ cell cytokine release in the response of CRSWNP and HMT to HSV1 infection (Figure 3C). The expression of IL-17 was only up-regulated in HMT tissues after 48 and 72 hours, but not in CRSwNP tissues. There was a significantly higher spontaneous release of IL-5 at $24(p=0.037)$ and 48 hours $(p=0.025)$ in CRSwNP vs. HMT, but this was independent from the impact of HSV infection. A significantly increased release of IL-10 was observed in CRSwNP vs. HMT at $48(p=0.004)$ and 72 hours $(p=0.004)$, which was significantly further increased by HSV1 infection at 72 hours $(p=0.031)$. No increase in IL-10 was observed in HMT samples.

\section{Discussion}

This study shows for the first time a major difference in the response of healthy mucosa vs. mucosal tissue derived from chronic rhinosinusitis with nasal polyps (CRSwNP) in response to viral exposure, in this case HSV1. CRSwNP mucosal tissue shows a significant deficit in IFN- $\gamma$ and IL-17 release within 24 to 72 hours after infection in comparison to healthy mucosa, at the same time releasing significantly higher levels of the proinflammatory cytokines IL-1 $\beta$ and TNF- $a$. These findings were 
associated with significantly higher viral invasion scores at 48 and $72 \mathrm{~h}$ in CRSwNP mucosa compared to those for the healthy mucosa, indicating that CRSwNP nasal tissue provides less antiviral activity and at the same time releases disease progressing factors, allowing HSV1 to easier penetrate and spread through CRSwNP tissues, although the viral replication was similar between tissues.

Mucosal environments in disease are characterized by a distinct set of cytokine profiles, which impact on the extracellular matrix including the basement membrane, the type of inflammation (neutrophil/eosinophil), the innate and adaptive immune responses to microorganisms, and finally the potential to resolve ongoing inflammation ${ }^{(19)}$. Mucosal inflammation in nasal polyps mainly is orchestrated by Th2 cytokines, characterized by an increased eosinophilic inflammation and formation of $\lg E$ antibodies. This endotype is associated with co-morbid asthma ${ }^{(15)}$ as well as recurrence of disease in Caucasian patients ${ }^{(20)}$. All 7 CRSwNP samples in this study were classified as IL-5 positive, with high IgE and ECP concentrations, and 2 out of 7 nasal polyp patients had mild asthma. This biochemical and clinical presentation contrasts to the healthy mucosa and asthma status of the control patients. The specific immune profile in Th2-biased CRSwNP has also been associated with defects in innate or adaptive immunity, such as the alternative activation of macrophages, the suppression of T regulatory activity ${ }^{(21,22)}$, or the epithelial barrier tight junction molecule expression ${ }^{(23,24)}$.

IFNs are critical for innate and adaptive immunity against viral, some bacterial and protozoal infections ${ }^{(25)}$. Type I IFNs (IFN- $\alpha$ and IFN- $\beta$ ) can be produced by all nucleated cells as the first line of host antiviral defense ${ }^{(26)}$. Type II IFN (IFN- $\left.\gamma\right)$, affects activities of macrophages, NK cells, dendritic cells (DC), and T cells by enhancing antigen presentation, cell trafficking, and cell differentiation and expression profiles, conveying antiviral signals from the innate to the adaptive immune response in order to fully activate host antiviral immunity ${ }^{(27)}$. Recently identified type III IFNs (IFN- $\lambda 1$, IFN- $\lambda 2$ and IFN- $\lambda 3$ ) can induce antiviral activity in a variety of target cells that express the IFN- $\lambda$ receptor ${ }^{(28)}$. Aberrant IFN expressions are associated with a number of inflammatory and autoimmune diseases. An inadequate response to HRV infection has been recently described in severe asthma, suggesting that the innate anti-viral response to viruses, here HRVs, may be impaired in those patients ${ }^{(29)}$.

The significant release of IFN- $\gamma$ in healthy mucosal tissue (HMT) samples at 48 and 72 hours is considered a normal response to a viral infection, whereas the lack of induction of IFN- $\gamma$ release upon HSV1 infection in CRSwNP tissues may result in a deficit to limit viral replication. Our previous findings demonstrated that HSV1 has an increased invasive ability into nasal polyp tissue accompanied by more serious damage of epithelium compared with nasal turbinate mucosa ${ }^{(16,17)}$. Also Type I and III IFNs have been shown to play an important role in combating HSV-1 infection, and studies have shown that the magnitude and swiftness of IFN- $\alpha / \beta$ induction correlates with the relative resistance of C57BL/6 mice to HSV-1 infection ${ }^{(30)}$. In this present study, IFN- $a$ could be detected in 4 out of 7 HMT samples after HSV1 incubation at 24 and 48 hours, but not in any CRSwNP samples. IFN- $\beta$ was found in the supernatants of 3 HMT and 4 CRSwNP samples at 72 hours incubation. These findings were rather inconsistent and did not reach significance, but may point to a broader defect in IFN response in CRSwNP tissue.

IL-17 and related components of Th17 immune function are increasingly identified as contributors to the pathogenesis of many infections, including respiratory infections caused by viruses. IL-17 facilitates the recruitment of neutrophils to the airways, and contributes to the clearance of the virus. In our human nasal mucosa model, normal healthy controls responded with a significant increase in IL-17 release upon HSV1 infection, whereas CRSwNP tissue also lacked this adequate immune response with possible consequences; unfortunately, the recruitment of neutrophils cannot further be investigated in this model.

Structural cells such as epithelial cells form part of the first line of defense and play a key role in the initiation of the immune responses including the release of IL-1 family members early on during the development of the inflammatory cascade. Secretion of IL-1 $\beta$ is an important outcome of the inflammasome activation, involving NF-kB activation and the expression of proinflammatory cytokines ${ }^{(30)}$. In the present study, we could demonstrate a significant release of IL-1 $\beta$ and TNF- $\alpha$ in CRSwNP tissue, whereas no IL-1 $\beta$ was released in HMT before $72 \mathrm{~h}$ post inoculation. This suggests that viral infection induces a more vivid inflammatory response in CRSwNP than in healthy control HMT. This observation is supported by a study reporting increased levels of the pro-inflammatory mediator IL-1 $\beta$ and one of its antagonists, IL-1 receptor antagonist (IL-1 ra), in nasal lavage of asthmatic, but not non-asthmatic patients during experimental rhinovirus infection ${ }^{(31)}$. Wang et al showed no difference in IL-6 and IL-8 release in healthy mucosa vs. nasal polyp tissue after HRV infection in-vitro ${ }^{(32)}$; in agreement with their findings, we also found no difference for IL-6 (IL-8 was not measured here), but well for other cytokines, prominently for type 2 IFN, IL-17, IL-1 $\beta$ and TNF- $\alpha$.

Herpes simplex virus (HSV)-specific T cells are essential for viral clearance. However, T cells do not prevent HSV during latent infection or reactivation. A recent study using PBMCs has shown that HSV-infected T cells stimulated through the TCR selectively synthesized IL-10, a cytokine that suppresses cellular immunity and favors viral replication ${ }^{(33)}$. This finding further was sup- 
ported by studies in mice showing that the immunoregulatory cytokine IL-10 is a key host factor in inducing and maintaining T cell exhaustion, facilitating viral persistence ${ }^{(34,35)}$. In fact, $9 \%$ of human nasal polyps were infected with HSV1 ${ }^{(10)}$, and persistent infections may contribute to this number. This hypothesis requires further research, focusing on IL-10 is a key player in the establishment and perpetuation of viral persistence.

As it is unethical to remove healthy ethmoidal mucosa from a non-diseased person, and it is seldom indicated to remove parts of the middle turbinate from healthy subjects; inferior turbinates have been used as controls for decades. We have shown in the past that inferior turbinates do show the same changes in terms of adaptive and innate immune reactions as the sinus mucosa in CRSsNP and CRSwNP (36). In that sense we may expect that healthy inferior turbinates do represent healthy sinus mucosa. We assume that the structural changes from nasal polyps to normal sinus mucosa are much greater than the differences from ethmoidal to turbinate mucosa. However, we have to admit the fact that the tissue is isolated and the model therefore is not suitable for studies on cell migration.

\section{Conclusion}

We here demonstrate for the first time in a human ex-vivo mucosal model that the response of tissues derived from nasal polyps of chronic rhinosinusitis (CRSwNP) patients vs. inferior turbinates of healthy subjects differs considerably upon viral infection by HSV1. CRSwNP shows a significant deficit in IFN- $\gamma$ and IL-17 response, but in contrast releases significantly higher amounts of the pro-inflammatory cytokines IL-1 $\beta$ and TNF- $a$, and IL-10. This inadequate response may be associated with a deeper intrusion of the virus upon acute infection, but also may lead to a different acute inflammatory response in CRSwNP tissue.

\section{Authorship contribution}

FL, XDW, CB, NZ developed the idea for this study, developed the ex vivo model, interpreted the data, and drafted the manuscript; HJN, LZ, NGP and SLJ contributed the experimental viruses and helped revising the paper. HJN provided the stock of the HSV1, SLJ provided the measurement of IFNs, GH did the cytokine measurements. All authors approved the final version of the manuscript.

\section{Acknowledgement}

This work was supported by grants to Claus Bachert from the European Commission's Seventh Framework programme under grant agreement $\mathrm{N}^{\circ} 260895$ (PREDICTA); from the Flemish Scientific Research Board, FWO, projects 1841713N, G.039412N G.067512N; BOF14/GOA/019 and the Interuniversity Attraction Poles Program -Belgian State Belgian Science Policy, Nr. IAP $\mathrm{P} 7 / 30$.

\section{Conflict of interest}

There is no conflict of interest by all authors.

\section{References}

1. Bachert C, Patou J, and Van Cauwenberge $P$. The role of sinus disease in asthma. Curr Opin Allergy Clin Immunol, 2006; 6: 29-36

2. Sykes $A$ and Johnston SL. Etiology of asthma exacerbations. J Allergy Clin Immunol, 2008;122: 685-8

3. Kusel MM, de Klerk NH, Kebadze T, et al Early-life respiratory viral infections, atopic sensitization, and risk of subsequent development of persistent asthma. J Allergy Clin Immunol, 2007; 119:1105-10.

4. Jackson DJ, Gangnon RE, Evans MD, et al Wheezing rhinovirus illnesses in early life predict asthma development in high-risk children. Am J Respir Crit Care Med, 2008, 178: 667-72.

5. DeMore JP, Weisshaar EH, Vrtis RF, et al. Similar colds in subjects with allergic asthma and nonatopic subjects after inoculation with rhinovirus-16. J Allergy Clin Immunol. 2009; 124:245-52

6. Corne JM, Marshall C, Smith S, et al. Frequency, severity, and duration of rhinovirus infections in asthmatic and nonasthmatic individuals: a longitudinal cohort study. Lancet. 2002; 359:831-4.

7. Xu F, Sternberg MR, Kottiri BJ, et al. Trends in herpes simplex virus type 1 and type 2 seroprevalence in the United States. JAMA 2006; 296: 964-973.

8. Bunzli D, Wietlisbach V, Barazzoni F, Sahli R Meylan PR. Seroepidemiology of Herpes Simplex virus type 1 and 2 in Western and Southern Switzerland in adults aged 25-74 in 1992-93: a population-based study. BMC Infect Dis 2004; 4: 10.

9. Rabenau HF, Buxbaum S, Preiser W, Weber B, Doerr HW. Seroprevalence of herpes simplex virus types 1 and type 2 in the Frankfurt am Main area, Germany. Med Microbiol Immunol (Berl) 2002; 190: 153160.

10. Zaravinos A, Bizakis J, Spandidos DA Prevalence of human papilloma virus and human herpes virus types 1-7 in human nasal polyposis. J Med Virol 2009; 81: 16131619.

11. Chacko J, Kuruvila M, Bhat GK. Factors affecting the nasal carriage of methicillinresistant Staphylococcus aureus in human immunodeficiency virus infected patients. Indian J Med Microbiol 2009; 27: 146-148.

12. Glorieux S, Favoreel HW, Meesen G, de Vos W, Van den Broeck W, Nauwynck HJ. Different replication characteristics of his- torical pseudorabies virus strains in porcine respiratory nasal mucosa explants. Vet Microbiol 2009; 136: 341-346.

13. Contoli M, Message SD, Laza-Stanca V, et al. Role of deficient type III interferon-lambda production in asthma exacerbations. Nat Med. 2006: 12:1023-6.

14. Fokkens WJ, Lund VJ, Mullol J, et al. EPOS 2012: European position paper on rhinosinusitis and nasal polyps 2012. A summary for otorhinolaryngologists. Rhinology. 2012; 50:1-12.

15. Bachert C, K van Steen, N Zhang, et al. Specific IgE against Staphylococcus aureus enterotoxins: an independent risk factor for asthma. J Allergy Clin Immunol. 2012; 130:376-381

16. Glorieux S, Bachert C, et al. Herpes simplex virus type 1 penetrates the basement membrane in human nasal respiratory mucosa. PLos One 2011; 6: e22160.

17. Wang X, Zhang N, Glorieux S, et al. Herpes simplex virus type 1 infection facilitates invasion of Staphylococcus aureus into the nasal mucosa and nasal polyp tissue. PLoS One 2012; 7:e39875.

18. Reed, L.J., Muench, H. (1938). A simple method of estimating fifty percent end- 
points. Am. J. Hygiene, 27, 493-497.

19. Akdis CA, Bachert C, Cingi C, et al. Endotypes and phenotypes of chronic rhinosinusitis: A PRACTALL document of the European Academy of Allergy and Clinical Immunology and the American Academy of Allergy, Asthma \& Immunology. J Allergy Clin Immunol 2013; 131:1479-90

20. Zhang N, Holtappels G, Claeys C, Huang $G$, van Cauwenberge $P$, Bachert $C$. Pattern of inflammation and impact of Staphylococcus aureus enterotoxins in nasal polyps from southern China. Am J Rhinol 2006; 20:445-50

21. Van Zele T, Holtappels G, Gevaert P, Bachert C. Differences in initial immunoprofiles between recurrent and non-recurrent chronic rhinosinusitis with nasal polyps. Am J Rhinol Allergy. 2014; 28:192-8

22. Van Bruaene N, Perez-Novo C, Basinski T, et al. $T$ cell regulation in chronic paranasa sinus disease. J Allergy Clin Immunol 2008; 121:1435-1441

23. Meng J, Zhou P, Liu Y, Liu F, Yi X, Liu S, et al. The development of nasal polyp disease involves early nasal mucosal inflammation and remodeling. PLoS One 2013; 8:e82373

24. Soyka MB, Wawrzyniak P, Eiwegger T, et al. Defective epithelial barrier in chronic rhinosinusitis: the regulation of tight junctions by IFN- $\gamma$ and IL-4. J Allergy Clin Immunol. 2012; 130:1087-1096.

25. Schoenborn JR, Wilson CB. Regulation of interferon-gamma during innate and adaptive immune responses. Adv. Immunol. 2007; 96: 41-101.
26. Khaitov MR, Laza-Stanca V, Edwards MR, et al. Respiratory virus induction of alpha-, beta- and lambda-interferons in bronchial epithelial cells and peripheral blood mononuclear cells. Allergy 2009; 64:375-86.

27. Saha B, Jyothi PS, Chandrasekar B, Nandi D. Gene modulation and immunoregulatory roles of interferon gamma. Cytokine. 2010; 50:1-14.

28. Gad HH, Dellgren C, Hamming OJ, Vends S, Paludan SR, Hartmann R. Interferon- lambda is functionally an interferon but structurally related to the interleukin- 10 family. J Biol Chem 2009; 284:20869-75.

29. Sykes A, Edwards MR, Macintyre J, et al. Rhinovirus 16-induced IFN-alpha and IFNbeta are deficient in bronchoalveolar lavage cells in asthmatic patients. J Allergy Clin Immunol 2012; 129:1506-14.e6.

30. Halford WP, Veress LA, Gebhardt BM, Carr DJ. Innate and acquired immunity to herpes simplex virus type 1. Virology. 1997; 236:328-37.

31. de Kluijver J, Grünberg K, Pons D, et al. Interleukin-1 $\beta$ and interleukin-1ra levels in nasal lavages during experimental rhinovirus infection in asthmatic and non-asthmatic subjects. Clin Exp Allergy 2003; 33:1415-8

32. Wang JH, Kwon HJ, Chung YS, Lee BJ, Jang YJ. Infection rate and virus-induced cytokine secretion in experimental rhinovirus infection in mucosal organ culture: comparison between specimens from patients with chronic rhinosinusitis with nasal polyps and those from normal subjects. Arch Otolaryngol Head Neck Surg.
2008 Apr;134(4):424-7

33. Sloan DD, Jerome KR. Herpes simplex virus remodels T-cell receptor signaling, resulting in p38-dependent selective synthesis of interleukin-10. J Virol. 2007; 81:12504-14.

34. Ejrnaes M, Filippi CM, Martinic MM, et al. Resolution of a chronic viral infection after interleukin-10 receptor blockade. J Exp Med. 2006; 203: 2461-2472

35. Brooks DG, Trifilo MJ, Edelmann KH, Teyton L, McGavern DB, Oldstone MB. Interleukin-10 determines viral clearance or persistence in vivo. Nature Medicine 2006; 12:1301-1309.

36. Van Crombruggen K, Van Bruaene N, Holtappels G, Bachert C. Chronic sinusitis and rhinitis: clinical terminology "Chronic Rhinosinusitis" further supported. Rhinology. 2010 Mar; 48(1): 54-8.

Nan Zhang, MD, PhD

Upper Airway Research Laboratory

Department of Otorhinolaryngology

Ghent University Hospital

De Pintelaan 185

9000 Ghent

Belgium

Tel: 0032478437628

E-mail: nan.zhang@ugent.be 